\title{
A Informação Tecnológica como Ferramenta para Gestão de Políticas Públicas de Saúde
}

\author{
TECHNOLOGICAL INFORMATION AS A TOOL \\ FOR HEALTH PUBLIC POLICIES MANAGEMENT
}

\author{
Luciene Ferreira Gaspar Amaral (*) \\ Érica Riskalla Anchite (**) $^{* *}$ \\ Carlos Eduardo Collazo Pontes ${ }^{(* * *)}$ \\ Tereza Cristina dos Santos ${ }^{(* * * *)}$ \\ Márcia Coronha Ramos Lima ${ }^{(* * * * * *)}$
}

\section{RESUMO}

Desde a promulgação da lei que regula direitos e obrigações relativos à Propriedade Industrial, Lei n. 9.279/96, baseada nos preceitos ditados pelo TRIPS - Trade-Related Aspects of Intellectual Property Right, a retomada da proteção dos produtos e processos farmacêuticos, inicialmente, através dos arts. 230-232 que possibilitaram a revalidação, no Brasil, de patentes concedidas no exterior, sem análise de mérito, vem sendo debatida em diversos foros. Embora não seja de opinião unívoca, é constante e acirrada a discução sobre a constitucionalidade do ato de se conceder o privilégio à uma suposta invenção sem análise dos requisitos básicos de patenteabilidade exigidos

(*) Química, doutora em Química de Produtos Naturais pela Universidade Federal do Rio de Janeiro (UFRJ); especialista em Propriedade Intelectual pela Pontifícia Universidade Católica do Rio de Janeiro (PUC-RJ); especialista sênior em Propriedade Industrial do Instituto Nacional de Propriedade Industrial.

$\left.{ }^{* *}\right)$ Farmacêutica Industrial, mestranda do Mestrado Profissional em Gestão, Pesquisa e Desenvolvimento na Indústria Farmacêutica por Farmanguinhos/FIOCRUZ e especialista em Farmácia Hospitalar pela Universidade Federal Fluminense (UFF); analista de Pesquisa de Farmanguinhos/ FIOCRUZ. E-mail:ericaanchite@fiocruz.br.

${ }^{(* * *}$ Farmacêutico, especialista em Saúde Pública pelo Centro Universitário Celso Lisboa; analista de Informação Tecnológica - Bolsista CNPq DTI-2 em Farmanguinhos/FIOCRUZ.

${ }^{* * * *}$ ) Farmacêutica, doutora em Química de Produtos Naturais pela UFRJ e Universittá Cattolica del Sacro Cuore em Roma, Itália; pesquisadora de Farmanguinhos/FIOCRUZ e do PPGVS/INCQS/ FIOCRUZ; coordenadora de Vigilância e Serviços Tecnológicos de Farmanguinhos/FIOCRUZ

$\left.{ }^{* \star * * *}\right)$ Bióloga, doutora em Biologia Celular e Molecular pela FIOCRUZ; pesquisadora Titular em Saúde de Farmanguinhos/FIOCRUZ; vice-diretora de Ensino, Pesquisa e Inovação de Farmanguinhos/FIOCRUZ. Recebido em 18.06.10. Aprovado em 28.06.10. 
internacionalmente, insculpidos no art. $8^{\circ}$ que se confunde com as acirradas discussões sobre a dualidade que permeia a concessão patentes a tecnologias utilizadas na produção de medicamentos considerados de interesse público e o direito à propriedade imaterial, ambos garantidos constitucionalmente. Em virtude dessas considerações, o presente documento destina-se a relatar a atividade que vem sendo implantada em Farmanguinhos, através da qual as tecnologias afetas à produção dos medicamentos é monitorada, como uma inovação na gestão pública, através da identificação de pontos mais relevantes a serem apreciados na análise de pedidos de patente ou patentes concedidas considerando o arcabouço jurídico nacional e internacional que norteia o sistema de propriedade industrial no Brasil à luz dos ditames constitucionais.

\section{Palavras-chave}

AIDS; Antirretroviral; Políticas Públicas; Propriedade Industrial.

\section{ABSTRACT}

With the enforcement of the law 9279/96, based on the guidelines of the Trade-related Aspects of Intellectual Property Right (TRIPS), the protection of pharmaceutical products, and using articles 230-232, enable once again in Brazil, the validation of patents granted in other countries without analyses of their claims. This validation, without analysis, is still subject of debate. There is no consensus on the constitutionality of the concession of privileges to a supposed invention without analyses of the basic international principles of patentability, listed in the $8^{\text {th }}$ article of the referred law. This discussion merges and can be confounded with a not less polemic discussion on the duality on the concession of patents of technologies used for the production of medicines of public interest and the right of immaterial property, both guaranteed in the Brazilian constitution. In this scenario, the current work describes in Farmanguinhos the implementation of technologies related to the production of medicines and its evaluation as innovation in the public sector. For this, the critical issues to be considered in the patent claim and approval are identified using as background the Brazilian and International laws that guide the industrial property in light of the Brazilian constitution.

\section{Keywords}

AIDS; Anti-retroviral ; Industrial Property; Public Policies. 


\section{INTRODUÇÃO}

Tendo em vista o disposto na Constituição Federal Brasileira de 1988, o governo brasileiro tem o dever de elaborar políticas que possibilitem o fornecimento de medicamentos gratuitamente à população. Tais políticas, implantadas pelo Ministério da Saúde, têm viabilizado o acesso da população a vários tipos de medicamentos, inclusive aqueles denominados de alto custo, indispensáveis para promover, proteger e recuperar a vida. De tal forma, são amplos os programas destinados à aquisição de medicamentos, que têm onerado consideravelmente o orçamento do Ministério da Saúde, prejudicando os investimentos em outras áreas da saúde, bem como na área social como um todo. Assim, é de extrema relevância para o governo federal manter o controle sobre as informações disponíveis a respeito das drogas comercializadas, bem como monitorar novas tecnologias a serem lançadas no mercado.

No objetivo de tornar possível o acesso às informações técnicas e jurídicas sobre os medicamentos dispensados pelo Ministério da Saúde, Farmanguinhos vem atuando, através da Coordenação de Vigilância e Serviços tecnológicos (CVST), junto ao Departamento de Assistência Farmacêutica (DAF) do Ministério da Saúde na compilação de dados e na elaboração de pareceres sobre a situação jurídica dos medicamentos, indicando possíveis estratégias de atuação, suas consequências e soluções. Desta forma, a ação possibilita aos gestores atuarem com clareza nas negociações com as empresas transnacionais detentoras dos direitos de patente referentes aos medicamentos excepcionais e de alto custo, de modo a agilizar e substanciar a política reguladora de preços de medicamentos.

\section{PANORAMA DO MERCADO DE MEDICAMENTOS}

A indústria de produtos farmacêuticos e medicinais compõe o setor produtivo brasileiro que vem movimentando, anualmente, recursos em torno de US\$ 10 bilhões, desde a década de 90 . Esse comportamento permitiu que a indústria farmacêutica brasileira fosse classificada, em 2001, como a quinta indústria farmacêutica mundial considerando-se o volume de produção, atrás apenas dos Estados Unidos, Japão, Alemanha e França(1)

(1) CANCHUMANI, Roberto Mario Lovón. A produção de fármacos e medicamentos no Brasil e na Índia: uma análise comparativa (1995-2001). In: CONGRESSO INTERNACIONAL EM INOVAÇÃO E GERENCIAMENTO (ICIM 2009): GERENCIAMENTO DE INOVAÇÕES VOLTADO AO DESENVOLVIMENTO SUSTENTÁVEL, 6. 2009, São Paulo, 2009. 
(Tabela 1)

\begin{tabular}{|c|c|c|}
\hline País & US\$ Bilhões & $\%$ \\
\hline EUA & 74,09 & $24,26 \%$ \\
\hline Japão & 38,76 & $12,69 \%$ \\
\hline Alemanha & 15,47 & $5,06 \%$ \\
\hline França & 14,16 & $4,32 \%$ \\
\hline Brasil & 10,31 & $3,37 \%$ \\
\hline Itália & 9,12 & $2,98 \%$ \\
\hline Reino Unido & 8,39 & $2,74 \%$ \\
\hline Espanha & 5,28 & $1,73 \%$ \\
\hline Canadá & 4,28 & $1,40 \%$ \\
\hline Mercado Total & 305,40 & $100,00 \%$ \\
\hline
\end{tabular}

Tabela 1: Principais Mercados Farmacêuticos no Mundo (Fiocruz, 2001) - Fonte: ABIQUIF/ABIFARMA/SINDUSFARMA

No que tange ao faturamento no ano de 2004, o tamanho do mercado farmacêutico foi estimado em torno de US $\$ 518$ bilhões em vendas nas farmácias e drogarias, valor que supera em $7 \%$ os dados do ano anterior. Segundo a publicação do IMS Health, 2005, a vendas globais são, em maioria, atribuídas a Estados Unidos, Japão e Europa, perfazendo cerca de $88 \%$, das quais $45 \%$ foram negociadas pelos Estados Unidos (IMS Health, 2005)(2).

Estudos recentes prevêem um crescimento em torno de 4 a $6 \%$ para o mercado mundial em 2010, devido ao movimento do mercado Europeu, que devem corresponder a $\$ 825$ bilhões de dólares. Devido à dinâmica observada no setor há previsões de se manter um crescimento de 4 a $7 \%$ até 2013 , levando-se em conta o impacto da macroeconomia global, a mudança no sistema inovador e produtos que já tenham alcançado a maturidade necessária para chegar ao mercado, bem como a crescente influência do acesso à saúde e o financiamento da demanda do mercado perfazendo um crescimento real que deverá atingir $\$ 975$ bilhões de dólares ${ }^{(3)}$.

\section{Mercado Farmacêutico - Brasil}

No estudo publicado recentemente por técnicos do GRUPEMEF (Grupo dos Profissionais Executivos do Mercado Farmacêutico) observa-se, desde

(2) IMS. Disponível em: <ttp://www.imshealth.com>.

(3) Id. Ibid 
1997, um crescimento considerável em termos de vendas nominais. No que tange as quantidades vendidas, observa-se um declínio no período de 1997 a 2003, ano em que apresentava apenas $65,3 \%$ da produção em relação a 1997. No entanto, em 2004, ocorreu uma mudança efetiva com incremento real de $11,37 \%$ nas vendas, que se mantiveram positivas, voltando apresentar decréscimo de 2,46\%, nos 12 meses móveis até dezembro de 2009, em relação às vendas em 1997. (Tabela 2 , gráficos 1 e 2) - (Sindusfarma, 2010)

\begin{tabular}{|c|c|c|c|c|c|c|c|c|c|}
\hline Ano & \begin{tabular}{|c|} 
Vendas \\
Nominais em \\
R\$ 1.000
\end{tabular} & Variação \% & \begin{tabular}{c|} 
Índice \\
Base: \\
$1997=100$
\end{tabular} & $\begin{array}{l}\text { Vendas em } \\
\text { US } \$ 1.000\end{array}$ & Variação \% & \begin{tabular}{|c|} 
Índice \\
Base: \\
$1997=100$
\end{tabular} & $\begin{array}{l}\text { Vendas em } \\
\text { US } \$ 1.000\end{array}$ & Variação \% & $\begin{array}{c}\text { Índice } \\
\text { Base: } \\
1997=100\end{array}$ \\
\hline 1997 & 9.210 .340 & - & 100 & 8.537 .436 & - & 100 & 1.854 .094 & - & 100 \\
\hline 1998 & 10.064 .780 & $9,28 \%$ & 109,3 & 8.660 .434 & $1,44 \%$ & 101,4 & 1.814 .337 & $-2,14 \%$ & 97,9 \\
\hline 1999 & 11.847 .533 & $17,71 \%$ & 128,6 & 6.537 .763 & $-24,51 \%$ & 76,6 & 1.778 .800 & $-1,96 \%$ & 95,9 \\
\hline 2000 & 12..281.749 & $3,67 \%$ & 133,3 & 6.705 .678 & $2,57 \%$ & 78,5 & 1.697 .822 & $-4,55 \%$ & 91,6 \\
\hline 2001 & 13.427 .727 & $9,33 \%$ & 145,8 & 5.685 .430 & $-15,21 \%$ & 66,6 & 1.640 .251 & $-3,39 \%$ & 88,5 \\
\hline 2002 & 14.985 .132 & $11,60 \%$ & 162,7 & 5.210 .328 & $-8,36 \%$ & 61,0 & 1.662 .190 & $1,34 \%$ & 89,6 \\
\hline 2003 & $16.934,356$ & $13,01 \%$ & 183,9 & 5.575 .005 & $7,00 \%$ & 65,3 & 1.526 .720 & $-8,15 \%$ & 82,3 \\
\hline 2004 & 20.190 .101 & $19,23 \%$ & 219,2 & 6.882 .028 & $23,44 \%$ & 80,6 & 1.700 .264 & $11,37 \%$ & 91,7 \\
\hline 2005 & 23.883 .373 & $18,29 \%$ & 259,3 & 9.905 .674 & $43,94 \%$ & 116,0 & 1.734 .378 & $2,01 \%$ & 93,5 \\
\hline 2006 & 25.924 .397 & $8,55 \%$ & 281,5 & 11.872 .675 & $19,86 \%$ & 139,1 & 1.759 .817 & $1,47 \%$ & 94,9 \\
\hline 2007 & 28.226 .836 & $8,88 \%$ & 306,5 & 14.626 .022 & $23,19 \%$ & 171,3 & 1.801 .274 & $2,36 \%$ & 97,2 \\
\hline 2008 & 31.027 .099 & $9,92 \%$ & 336,9 & 17.154 .669 & $17,29 \%$ & 200,9 & 1.819 .757 & $1,03 \%$ & 98,1 \\
\hline $2009^{\star}$ & 33.649 .115 & $8,45 \%$ & 365,3 & 17.183 .573 & $0,17 \%$ & 201,3 & $1.775,025$ & $-2,46 \%$ & 95,7 \\
\hline
\end{tabular}

Tabela 2: MERCADO FARMACÊUTICO - BRASIL Vendas Nominais em R\$ 1000 e US\$ 1000 (sem impostos) e em 1000 Unidades - Período: 1997 a 2009* Fonte: GRUPEME/Febrafarma - Depto. de Economia.

OBS: * 12 meses móveis até dezembro de 2009 — Dados sujeitos à retificação 


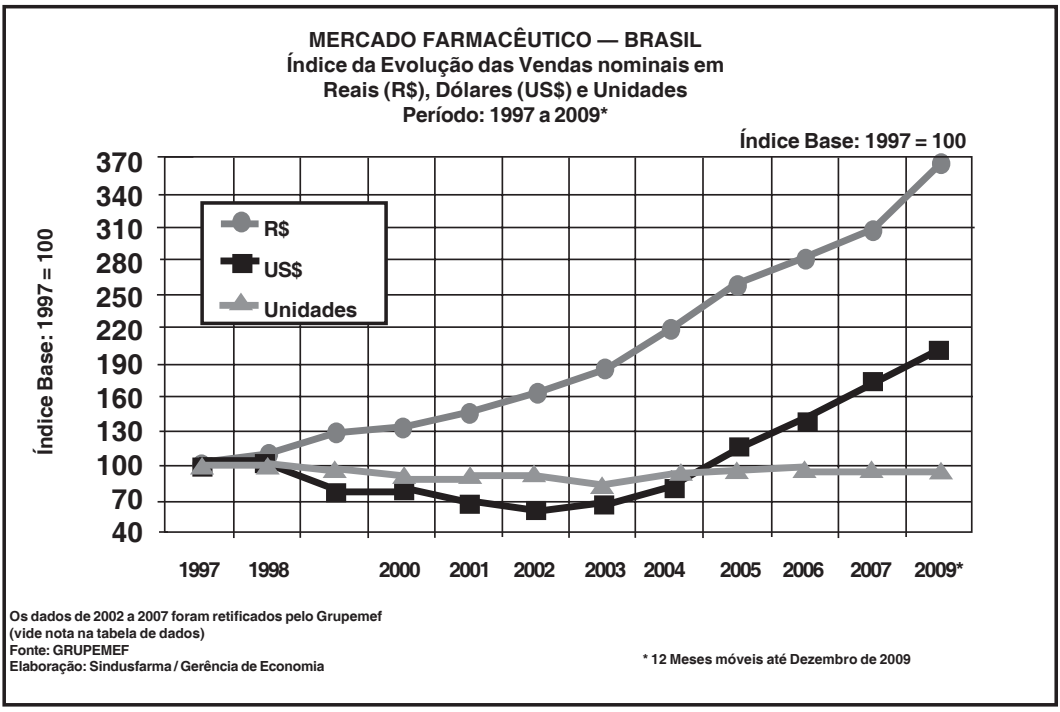

Gráfico 1: Mercado Farmacêutico - Brasil. Índice da evolução das vendas nominais em Reais (R\$), Dólares (US\$) e Unidades no período de 1999 a 2009*.

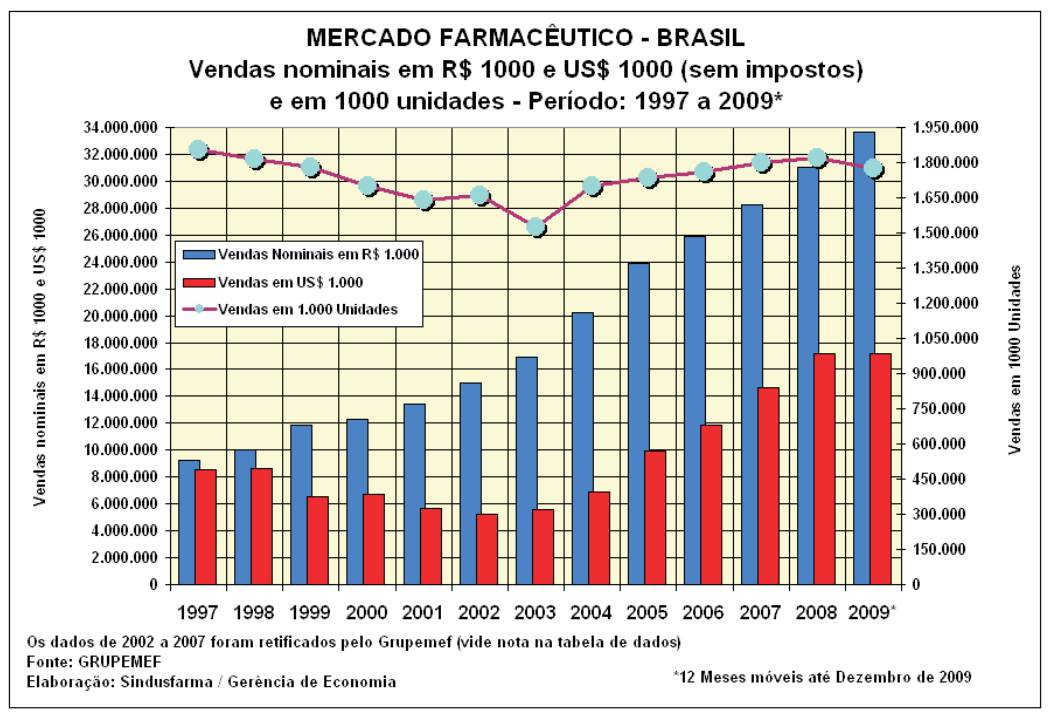

Gráfico 2: Mercado Farmacêutico - BRASIL. Vendas nominais em R\$ 1000 e US\$ 1000 (sem impostos) e em 1000 unidades - Período: 1997 a 2009* 
Segundo dados publicados pela $\operatorname{ABRAFARMA}^{(4)}$, as vendas de medicamentos em 2009 alcançaram o faturamento de, aproximadamente, $\mathrm{R} \$ 10.458$ bilhões, comprovando um aumento de $24,79 \%$ em relação a 2008

As vendas de medicamentos representaram $72,56 \%$ do faturamento do ano considerando as vendas brutas dos produtos comercializados pelos representantes do mercado. Mesmo com valores inferiores aos obtidos para a variação nas vendas realizadas em 2007 e 2008, em torno de $26 \%$, os medicamentos genéricos mantiveram taxa positiva confirmando ganhos em torno de $23,54 \%$ em 2009. Contudo, o Programa Farmácia Popular apresenta o faturamento negativo em 2009 quando comparado aos valores de 2008, como evidenciado na tabela 2 .

\begin{tabular}{|c|c|c|c|c|}
\hline Indice & 2008 & 2009 & Var & Particip \\
\hline Vendas & $11.567 .944 .689^{r}$ & 14.413 .926 .002 & $24,60 \%$ & \\
\hline Vendas em medicamentos & 8.380.962.979 & 10.458 .670 .872 & $24,79 \%$ & $72,56 \%$ \\
\hline Vendas em năo-medicamentos & $3.186 .981 .710^{\prime}$ & 3.955 .255 .131 & $24,11 \%$ & $27,44 \%$ \\
\hline Vendas em medicamentos genéricos & $1.187 .400 .326^{\prime}$ & 1.466 .873 .388 & $23,54 \%$ & $14,03 \%$ \\
\hline Vendas com entrega em domicilio & 630.257 .503 & 720.757 .604 & $14,36 \%$ & $5,00 \%$ \\
\hline Vendas no Programa Farmácia Popular & $169.458 .188^{\prime}$ & 147.934 .053 & $-12,70 \%$ & \\
\hline Clientes atendidos & $449.801 .365^{\prime}$ & 502.449 .503 & $11,70 \%$ & \\
\hline Clientes atendidos - entrega em domicili & 12.316.309 & 12.557 .951 & $1,96 \%$ & \\
\hline Clientes atendidos - farmácia popular & $7.265 .904^{\prime \prime}$ & 6.710 .926 & $-7,64 \%$ & \\
\hline Unidades vendidas & $1.195 .798 .724^{\prime}$ & 1.349 .236 .433 & $12,83 \%$ & \\
\hline Unidades vendidas - farmácia popular & $16.070 .008^{\prime}$ & 14.152 .369 & $-11,93 \%$ & \\
\hline Total de Lojas & 2.705 & 3034 & $12,16 \%$ & \\
\hline Lojas que Operam 24 Horas & 409 & 415 & $1,47 \%$ & \\
\hline Total de Colaboradores & 59.310 & 66575 & $12,25 \%$ & \\
\hline Total de Colaboradores - Farmacêuticos & 4.917 & 6437 & $30,91 \%$ & $9,67 \%$ \\
\hline Farmacêutico por loja & 1,82 & 2,12 & $16,72 \%$ & \\
\hline
\end{tabular}

Tabela - 2: Faturamento das farmácias e drogarias nos anos 2008 e 2009. (ABRAFARMA, 2010)

\section{Diagnóstico}

De acordo com o panorama traçado por técnicos do Centro de Biotecnologia Molecular Estrutural - $\mathrm{CBME}^{(5)}$, o setor industrial farmacêutico têm sido dominadas por empresas internacionais, as plantas de produção e formulação, instaladas no Brasil alcançam faturamento mundial superior a US $\$ 200$ bilhões e, destinando um montante de recursos, estimado em torno de US\$ 50 a US\$ 100 bilhões, para a bioindústria mundial. No Brasil, segundo estudo da Associação Brasileira de Bioindústria, os setores que utilizam a biotecnologia abrangem de $5 \%$ a $6 \%$ do Produto Interno Bruto.

(4) ASSOCIAÇÃO BRASILEIRA DE REDES DE FARMÁCIAS E DROGARIAS. Disponível em: <http:/ /www.abrafarma.com.br/imprensa.htm>.

(5) CENTRO BIOMEDICINA MOLECULAR E ESTRUTURAL. Disponível em: <http://www.cbme.ualg.pt/>. 
Ademais, constatam que, atualmente, as empresas de capital nacional são responsáveis por apenas $20 \%$ do faturamento do setor, centralizando as principais atividades em pesquisa e desenvolvimento de processos voltados à produção de produtos similares, durante o período em que o país não concedia patentes para produtos e processos farmacêuticos ou focavam sua produção em processos obtidos através de tecnologia transferida por empresas internacionais como as quais trabalhava em parceria, negociando a participação financeira no seu capital, ou o pagamento de royalties às empresas detentoras das patentes.

Após o licenciamento compulsório do Efavirenz, exemplo clássico da ação do Ministério da Saúde no incentivo ao fortalecimento das indústrias farmoquímica e farmacêutica nacional, o país emerge fortalecido em todos os pontos da cadeia desde a negociação da tecnologia até o abastecimento do Sistema Único de Saúde, com unidades farmacêuticas fabricadas, pela metade do valor através de tecnologia desenvolvida em solo brasileiro pelos técnicos de Farmanguinhos em parceria com o Laboratório LAFEPE, e as empresas nacionais Globe Química, Cristália e Nortec Química.

É sabido que ainda vivemos uma realidade crítica, haja vista os investimentos vultosos, da ordem de 10 a $15 \%$ do faturamento, realizados pelas empresas farmacêuticas mundiais, em pesquisa e desenvolvimento, visando consolidar uma estratégia competitiva, que objetiva lançar novos produtos, principalmente medicamentos patenteados, os quais Ihes garantem uma boa fatia do mercado. Ainda assim, possibilitam alcançar outras áreas investindo fortemente em pesquisas para obtenção de produtos obtidos através das tecnologias emergentes viabilizando fusões com empresas menores especializadas, com intuito de investir fortemente em Biotecnologia ou nanotecnologia dificultando, assim, o avanço da indústria de genéricos.

A promulgação da Lei de Patentes, Lei 9279/96, que prevê a proteção de produtos e processos farmacêuticos no País, através da qual foi inserida a proteção para os fármacos e medicamentos pelo dispositivo conhecido como pipeline, implicou em evasão significativa de recursos exportados com pagamento de licenças e royalties.

Contudo, por menor que tenha sido o investimento, até os dias de hoje, e por mais adverso que tenha sido o ambiente até então, ao investir efetivamente em novos produtos, o país aproveita a oportunidade única de ingressar gradativamente no mercado mundial estimado em centenas de bilhões de dólares anuais fortalecendo a indústria nacional, além de trabalhar no sentido de minimizar os problemas causados pela hegemonia a muito ostentada pelas empresas estrangeiras, que ocasiona o direcionamento do foco das pesquisas para medicamentos que atendem apenas aos mercados dos países desenvolvidos, os quais representam maior parcela de rentabilidade do mercado, deixando de realizar estudos voltados à descoberta de novos fármacos que atendam às demandas das doenças endêmicas típicas de países em desenvolvimento. 
A introdução dos medicamentos genéricos no mercado mundial que acirra a competição, a crise mundial que favorece as fusões das empresas, as inovações nos trâmites para a aprovação dos novos insumos farmacêuticos, além dos custos envolvidos para o desenvolvimento de novas moléculas, induzem os laboratórios a repensar suas decisões nesse ambiente competitivo e mutável, no afã de racionalizar a utilização dos recursos.

No que tange à questão patentária, a polêmica é constante quando se trata de delimitar direitos e deveres das empresas detentoras do privilégio, visto que o direito à vida e a propriedade imaterial são direitos e garantias constitucionais previstos no caput e no inciso XXIX do art. 5 da CFRB/88.

Em verdade, toda a polêmica gira em torno das estratégias utilizadas pelas empresas para manter o monopólio sobre o medicamento através de extensões obtidas sob a forma de novas apresentações do mesmo objeto, tais como as patentes de segundo uso, composições e combinações diversas, bem como patentes para diversas formas polimórficas e as patentes de seleção.

Recentemente, esta prática tornou-se evidente com a iminência de expiração de, pelo menos, 23 patentes até 2011, dentre as quais se destacam as patentes que protegem os medicamentos Viagra, Liptor, Xalatan, Diovan, Singulair e Atacand, fato que vem redirecionando a ação de algumas das empresas detentoras da tecnologia no sentido de produzirem as versões genéricas de seus produtos.

\section{A INOVAÇÃO NO ÂMBITO DAS POLÍTICAS PÚBLICAS DE SAÚDE}

O mercado brasileiro de medicamentos apresenta características singulares. Por um lado, existem medicamentos que não possuem nenhuma proteção econômica, pois suas patentes já expiraram; por outro, muitos princípios ativos possuem patentes ou um apelo à marca muito grande, o que lhes confere um quase monopólio. Sendo assim, o preço é fixado levando-se em consideração fatores da empresa detentora ou relacionado ao marketing.

Sabe-se que a descoberta de novas drogas envolve alta tecnologia e a consequente necessidade de pessoal qualificado para pesquisa e desenvolvimento de novos princípios ativos. Novas tecnologias, como química combinatorial, ensaios de atividade em larga escala robotizada (highthroughput screening), o planejamento de drogas baseado em estruturas e a utilização extensiva da bio-informática estão, hoje, no topo da agenda dos investimentos.

Já as multinacionais aqui instaladas não se dedicavam à pesquisa e desenvolvimento de novos princípios ativos por não haver no país, até 
recentemente, uma lei de patentes que lhes favorecesse, e também pelos já identificados problemas de ordem estrutural: ausência de política de incentivo a estas atividades e de política científica e tecnológica que orientasse o desenvolvimento da ciência e o estímulo à formação dos pesquisadores para trabalhar tanto nos laboratórios das universidades e institutos de pesquisa, quanto nas empresas farmacêuticas.

Em vista disto, é um desafio elaborar normas que atendam com eficácia às determinações constitucionais e, ao mesmo tempo cumpram o dever estatal de proporcionar o acesso universal aos medicamentos disponíveis no mercado sem interferir no comando constitucional.

Em 1998, com o lançamento da política de medicamentos consoante às diretrizes da Organização Mundial de Saúde (OMS), através da Portaria 3.916/ 98, o Ministério da Saúde estabeleceu regras básicas e diretrizes para ações setoriais, dentre elas, foram identificadas como prioritárias a adoção de Relação Nacional de Medicamentos Essenciais - RENAME; a reorientação da Assistência Farmacêutica organização das atividades de vigilância sanitária de medicamentos. Entretanto, ainda estão previstas as promoções do uso racionais de medicamentos, desenvolvimento científico e tecnológico; promoção da produção de medicamentos; garantia da segurança, eficácia e qualidade dos medicamentos; desenvolvimento e capacitação de recursos humanos.

No âmbito da Política Nacional de Medicamentos, a Política de incentivo aos medicamentos genéricos, através da Lei n. 9.787, de 1999, procurou enfrentar o problema da elevação de preços dos medicamentos pelo aumento da concorrência, aumentando o acesso e o uso racional dos medicamentos e funcionando como regulador de preços. Neste sentido, vale considerar que a Lei de Patentes permite que, aproximadamente, $80 \%$ dos medicamentos disponíveis no mercado brasileiro tenham versões genéricas.

Dentre algumas ações governamentais desenvolvidas na tentativa de implementar uma política industrial de medicamentos destacam-se: melhoria dos processos de aquisição com novos processos, através dos quais passou-se a contemplar processos licitatórios com um item de cada vez, possibilitando a participação de um maior número de empresas, o que gera baixa significativa de preços; além disso, os trâmites burocráticos foram simplificados e, a transparência dos preços praticados foi privilegiada com a criação da CEMD pela Lei n. 10.742/2003 Art. 5을 a quem compete a regulação econômica do mercado de medicamentos, voltados a promover a assistência farmacêutica à população, por meio de mecanismos que estimulem a oferta de medicamentos e a competitividade do setor além de dar transparência e publicidade aos critérios de ajuste de preço e índices utilizados para tal, de acordo com o art. 4의 $\S 1^{\circ}$ e $2^{\circ} \mathrm{c} / \mathrm{c} \S 6^{\circ}$.

Art. 5o Fica criada a Câmara de Regulação do Mercado de Medicamentos

- CMED, do Conselho de Governo, que tem por objetivos a adoção, 
implementação e coordenação de atividades relativas à regulação econômica do mercado de medicamentos, voltados a promover a assistência farmacêutica à população, por meio de mecanismos que estimulem a oferta de medicamentos e a competitividade do setor.

Ademais, observa-se a priorização do fortalecimento da produção estatal destacando-se a rede de laboratórios oficiais os quais, embora contem com investimentos do Ministério da Saúde, apresentam algumas dificuldades em seu funcionamento, conquanto sua produção seja essencial para a rede assistencial pública, desempenhando papel de fornecedor de medicamentos de qualidade e de regulador e controlador de preços.

Dentre as recentes ações com vistas ao fortalecimento da indústria farmacêutica nacional, o Ministério da Saúde lançou o Complexo Industrial da Saúde em 2006(6).

\section{DA ATUAÇÃO DE FARMANGUINHOS}

O setor responsável por gerar as informações tecnológicas na Coordenação de Vigilância e Serviços Tecnológicos de Farmanguinhos tem como função precípua identificar, monitorar e prospectar informações sobre fármacos e medicamentos utilizados nos programas de dispensação do Ministério da Saúde visando a redução dos custos de aquisição.

A realização do monitoramento e prospecção das tecnologias utilizadas para a produção dos medicamentos dispensados pelo SUS - Sistema Único de Saúde - seguem uma metodologia básica visando mapear a situação patentária do medicamento no mundo, em especial no Brasil, apontando os objetos protegidos no país que possam impedir a fabricação do insumo farmacêutico ou das diversas composições contendo o princípio ativo.

Para tanto, é imprescindível buscar e identificar todos os artigos científicos, os documentos de patente nacionais e internacionais que discorram sobre o insumo farmacêutico, o medicamento e as tecnologias envolvidas em sua produção que possam basear uma argumentação sólida contra a concessão indevida de outras patentes.

Os dados assim identificados são analisados e confrontados com os resultados obtidos a partir da análise dos autos dos pedidos de patentes brasileiras, buscando-se delimitar os objetos específicos de proteção, detectar as irregularidades técnicas e jurídicas que possam ser questionadas, relatá-las a fim de indicar as estratégias a serem adotadas em cada caso, informando as implicações técnicas e jurídicas envolvidas.

(6) GADELHA, Carlos Augusto Grabois. O complexo industrial da saúde e a necessidade de um enfoque dinâmico na economia da saúde. Ciência \& Saúde Coletiva, Rio de Janeiro, v. 8, n. 2, p. 521-535, 2003. 
Dessa prática, são gerados os resultados posteriormente transformados em pareceres para cada medicamento através dos quais são apresentadas as estratégias e/ou bases jurídicas que permitam o desenvolvimento tecnológico, tais como exceção bolar, licença voluntária, licença compulsória, nulidade da patente (administrativa ou judicial). Além de subsidiar a elaboração dos pareceres técnico-jurídicos a serem protocolados no INPI a fim de subsidiar o exame técnico realizado pelo corpo de especialistas.

Desta forma, as demandas geradas internamente ou provenientes do Ministério da Saúde estimulam ações específicas que visam:

- monitorar constantemente tecnologias relacionadas aos medicamentos existentes, bem como novos medicamentos lançados no mercado em substituição aos existentes e aqueles empregados em novas indicações terapêuticas;

- identificar os pedidos de patente dos medicamentos de interesse, já comercializados ou em desenvolvimento, além de coletar constantemente documentos de patente e artigos científicos de modo a subsidiar a pesquisa e o desenvolvimento de novos medicamentos em Farmanguinhos, visando a produção interna ou a transferência de tecnologia;

- acompanhar o trâmite processual desses pedidos de patente junto ao INPI;

- elaborar pareceres que subsidiem as decisões da Diretoria de Farmanguinhos em conjunto com o Ministério da Saúde;

- redigir subsídios a exame técnico de patentes (oposições), de modo a evitar a concessão indevida de patentes de medicamentos listados em programas de dispensação do Ministério da Saúde.

\section{DOS ESTUDOS REALIZADOS}

Os medicamentos de alto custo disponibilizados pelos programas do governo devem ser estudados caso a caso, através do levantamento de informações que, depois de analisadas, serão consolidadas em relatório e propiciarão a identificação da melhor estratégia para redução de gastos e agregação tecnológica, dentre as quais podemos citar:

A fabricação do insumo farmacêutico e do medicamento correspondente, pelos laboratórios oficiais ou por empresas nacionais farmoquímicas ou de medicamentos em parceria, caso as patentes estejam em domínio público;

Substituição do medicamento referência (com patente em vigor) por outro com efeitos equivalentes, cuja patente encontre-se em domínio público, que possa ser produzido a um custo mais baixo; 
Obtenção de licenciamento voluntário para produzir o medicamento no Brasil, negociação com o laboratório detentor da patente do medicamento para diminuição de preço;

Licenciamento compulsório da patente no Brasil, por interesse público ou abuso de poder econômico;

Identificação dos demais dispositivos, apontados como flexibilidades do acordo TRIPS, tais como exceção bolar e subsídio ao exame;

Utilização dos estudos realizados para auxiliar na pesquisa e desenvolvimento que venham sendo realizados tanto em Farmanguinhos como nos demais laboratórios oficiais;

A partir das informações coletadas através da pesquisa, desenvolvimento de princípios ativos e/ou formulações que se encontrem em estudo e, posteriormente, possam vir a se tornar ameaça para o Ministério da Saúde.

\section{RESULTADOS}

\section{Dos antirretrovirais: Efavirenz e Tenofovir}

Os estudos de vigilância epidemiológica das DST/HIV e AIDS fornecem os dados primordiais para basear a elaboração de estatísticas nacionais de morbidade e mortalidade desses agravos com vistas a auxiliar o entendimento dos mecanismos de disseminação, os quais possibilitam a proposta de alternativas de intervenção. No entanto sabe-se que, além da metodologia existente, há necessidade de se envidar esforços para que o sistema de vigilância atualmente adotado para as DST/HIV e AIDS seja reforçado no afã de incorporar ao sistema, a vigilância de segunda geração, com o intuito de propiciar a inserção de evidencias como o reconhecimento da heterogeneidade dos padrões epidêmicos e sua dinâmica, com foco nas populações mais vulneráveis; utilização de dados comportamentais associados às informações biológicas; utilização de fontes complementares de dados que possam melhorar a informação sobre comportamento, coinfecções, óbitos, variabilidade viral, doenças sexualmente transmissíveis, dentre outras.

Ainda assim, os estudos realizados através da metodologia existente nos fornecem os dados para que se possa afirmar que, desde a década de 80 até meados de 2007, foram identificados 474.273 casos de AIDS, a partir de estudos baseados na incidência de casos no país e macrorregiões em 2004 e 2005, conjugado com a estimativa de crescimento populacional para o período de 2006 a 2011. A partir desses dados, calcula-se que 220.730 novos casos serão detectados. 
Com vistas a viabilizar a estabilização das taxas atuais de infecção pelo HIV, a diminuição dos elevados índices de casos de AIDS, a redução da mortalidade e a melhoria da qualidade de vida dos portadores do vírus; urge que sejam estudados investimentos em planejamento para possibilitar a melhoria da qualidade de vida desses pacientes já tão sacrificados.

Neste contexto, o governo brasileiro vem elaborando políticas que favoreçam o fornecimento de medicamentos gratuitos, tendo em vista o disposto na Constituição Federal Brasileira de 1988. Tais políticas, implantadas pelo Ministério da Saúde (MS), têm viabilizado à população o acesso aos medicamentos necessários para promover, proteger e recuperar a vida, inclusive àqueles denominados de alto custo. Contudo, a aquisição de medicamentos tem onerado de forma considerável o orçamento do MS, inviabilizando o investimento em outras áreas de saúde, bem como na área social. Assim, há que se considerar de extrema relevância para o governo federal, manter o monitoramento constante das drogas já comercializadas, bem como aquelas correspondentes às novas tecnologias, prestes a serem lançadas no mercado para que se possa evitar um colapso das finanças em um curto espaço de tempo.

Entretanto, sabe-se que as informações científicas, técnicas, estratégicas e jurídicas das quais o Ministério da Saúde necessita para a regulamentação da aquisição e distribuição desses medicamentos se encontra, de certa forma, dispersas em diversas bases de dados ou portais informativos na Internet sejam gratuitos ou pagos, e precisam ser resgatadas e analisadas com a finalidade de subsidiar as decisões dos gestores responsáveis pelos programas.

Assim, desde 2005 a diretoria de Farmanguinhos vem envidando esforços, investindo em sua área técnica especializada em Propriedade Industrial, no afã de viabilizar a implantação de uma atividade rotineira visando a implementação de uma metodologia de coleta, análise e tratamento de informação que possibilite a elaboração dos pareceres que vêm subsidiando aos gestores de Farmanguinhos e do Ministério da Saúde, de modo a agilizar e substanciar as políticas de dispensação e reguladoras de preços de medicamentos.

Dos 17 medicamentos que compõem o coquetel anti-AIDS distribuído pelo governo, oito são produzidos localmente. Desde 2005, o então diretor do Programa Nacional de DST/AIDS, Pedro Chequer, já afirmava que o Brasil poderia economizar 600 milhões de dólares (que poderiam ser investidos em pesquisa, em cinco anos), com a produção local de três medicamentos protegidos por patente, dos quais o país, à época, já detinha a tecnologia. Portanto, teria capacidade para fabricá-los. Sabe-se que, até o início de 2007, os medicamentos anti-AIDS Efavirenz (Merck Sharp \& Dohme), Kaletra (Abbott) e Tenofovir (Gilead Science) consumiam 70\% dos recursos destinados anualmente para o programa. 
Após a constatação de que o Programa vinha sendo onerado em $70 \%$ de seu orçamento com a aquisição desses três medicamentos, dispensados aos pacientes cadastrados, Farmanguinhos vem atuando diretamente em todas as fases das estratégias montadas para minimizar os custos.

Uma vez identificado que o alto custo dos medicamentos estava relacionado com o monopólio atribuído ao fabricante, por intermédio de uma patente concedida ou um pedido de patente, fez-se necessário o estudo detalhado desses documentos para estabelecer as condições técnicas e jurídicas em que se encontravam.

A Lei de Propriedade Industrial (Lei 9279/96 — LPI), em seu art. 8o, determina que sejam patenteáveis apenas as invenções que atendam aos requisitos de novidade, atividade inventiva e aplicação industrial. A aferição da novidade impõe que a tecnologia ainda não tenha sido publicada, em qualquer país. A atividade inventiva pressupõe que a inovação não decorra de maneira óbvia do estado da técnica, ou seja, não possa ser reproduzida por um técnico no assunto com fulcro na literatura acessível ao público. No que tange à aplicação industrial, é necessário que e a tecnologia seja passível de ser produzida em escala industrial, com garantias de obtenção de um produto final que mantenha as características do produto aprovado para comercialização. Da redação do art. $8^{\circ}$, depreende-se que os ditos requisitos devem ser buscados cumulativamente durante a análise do pedido de patente. Dessa forma, uma invenção que não cumpra qualquer um dos requisitos legais não deve ser considerada patenteável, ou seja, seu objeto deve ser considerado como não patenteável ao qual o INPI não poderá proteger através da concessão de uma patente sob pena de causar danos à saúde pública, infringindo, diretamente, o preceito constitucional que impõe ao Estado a obrigatoriedade quanto ao subsídio à saúde da população.

Como resultados positivos provenientes desses estudos, ressalta-se o Licenciamento Compulsório das patentes referentes à tecnologia de produção do medicamento Efavirenz, decretado pelo Presidente da República através do Decreto n. ${ }^{\circ} 6108$ de 04/05/2007, por meio do qual se iniciou a reversão desse quadro. Destaca-se, ainda, a intervenção de Farmanguinhos na concessão do pedido de patente para o medicamento Tenofovir - PI 9811045-4 — que veio a se indeferido, em agosto de 2008.

Adite-se a essas ações a atuação de Farmanguinhos no processo de concessão de uma das patentes que visam proteger a tecnologia de obtenção do medicamento Kaletra, através da apresentação de um subsídio ao exame da patente PI 1100190-4 protocolado em 06/03/2006 junto ao INPI, ainda não analisado, embora o dito medicamento seja constatadamente de interesse público, com utilização frequente no kit do programa de violência contra a mulher. 


\subsection{Efavirenz}

Medicamento utilizado como parte da terapia contra o vírus HIV, o efavirenz alcançou venda de US\$ 726 milhões no mercado mundial em 2005. Foi patenteado no país pela Merck \& Co em 1999, com vigência até 2016. Seu preço no Brasil é $50 \%$ acima do preço referido para países com médio desenvolvimento. Tal cifra apontou para negociação de licença voluntária entre 2003-2005. Porém, com a concessão do registro concedido pela ANVISA ao Efavirenz similar para o Laboratório LAFEPE, a Merck esvaziou a negociação, retardando o fluxo de informações.

O Efavirenz é medicamento importado mais utilizado na terapia antirretroviral. Atualmente $38 \%$ dos pacientes utilizam esse medicamento. Estima-se que, até o final de 2007, 75 mil das 200 mil pessoas em terapia antirretroviral estarão usando esse fármaco. Além disso, a programação de compra para 2007, somente do Efavirenz 600mg, ao custo atual (US\$1,59/ comprimido) equivale a US\$ 42.930.000, ou seja, cerca de US\$580 por paciente/ano. (MINISTÉRIO DA SAÚDE, 2008.)

Nas tratativas iniciadas em novembro de 2006, a Merck propôs cooperação até 2011, quando se faria a transferência de tecnologia para Farmanguinhos e redução de $12 \%$ no custo. No entanto, a transferência ocorreria em data próxima à expiração da patente do Efavirenz e a redução refletia apenas o valor da isenção tributária de importação do insumo. Assim, o acordo proposto fugia a todos os preceitos do interesse nacional, por isso, foi recusado. O governo brasileiro solicitou a Merck a redução do preço do medicamento aos mesmos níveis ofertados à Tailândia, mas a proposta não foi aceita.

Fracassadas as negociações, no afã de cumprir a contento o disposto no Art. 196 da CRFB/88, o governo brasileiro utilizou-se do licenciamento compulsório, previsto no art. 31 do Acordo TRIPS, que permite ao país utilizar o produto patenteado em casos específicos de prevalência do interesse público, em combinação com o disposto nos arts. 68 a 74 da LPI, além dos decretos 3201/99 e 4830/03, que regulamentam o art. 71 da Lei n. 9.279/96, todos integrantes do arcabouço legal brasileiro.

Desde o início das negociações, ainda pelos idos de 2003, Farmanguinhos participou ativamente das ações em prol do licenciamento voluntário da tecnologia em questão para o Brasil.

Destarte, Farmanguinhos, por meio de sua equipe técnica, iniciou os preparativos para a adequação técnica voltada ao desenvolvimento da citada formulação de modo a atender às necessidades prementes do Ministério da Saúde em tempo hábil. Em uma ação conjunta com parceiros da indústria farmacêutica nacional, foram realizados investimentos destinados à obtenção do insumo farmacêutico do medicamento referência, com vistas à elaboração 
dos testes de validação de métodos analíticos, ensaios de equivalência farmacêutica e bioequivalência, bem como o desenvolvimento da formulação propriamente dita, iniciativa que possibilitou a decisão do Ministério da Saúde em 2007.

Com a declaração de interesse público, tornou-se iminente a declaração da licença compulsória. Assim, os técnicos de Farmanguinhos, em conjunto com técnicos do Ministério da Saúde, visitaram o Laboratório Farmacêutico do Estado de Pernambuco — LAFEPE — que já realizavam em seus laboratórios pesquisas para o desenvolvimento da formulação do efavirenz $600 \mathrm{mg}$, a fim de propor uma parceria, unindo forças para o desenvolvimento da formulação, em função do bem comum.

Concomitante ao processo de interação dos laboratórios, especialistas em propriedade industrial de Farmanguinhos preparavam parecer identificando as patentes cujos objetos perfaziam a tecnologia a ser licenciada, a fim de propiciar o desenvolvimento das formulações e do insumo farmacêutico no território nacional.

Decretado o licenciamento compulsório através do Decreto Presidencial n. 6.108/07, de 06/05/2007, o presidente da República, Luiz Inácio Lula da Silva, concede o licenciamento compulsório, por interesse público, de patentes referentes ao EFAVIRENZ, para fins de uso público não-comercial, inaugurando uma nova fase nas relações internacionais, onde o Brasil passa da ameaça à ação efetiva para garantir a sobrevivência das políticas públicas de saúde.

Ato contínuo, no afã de dar continuidade as tratativas foi instituído um grupo técnico composto pelo secretário de Ciência, Tecnologia e Insumos Estratégicos (SCTIE) do MS, secretário de Vigilância em Saúde do MS, diretora do Programa Nacional de DST/AIDS da SVS, diretor do DAF da SCTIE, diretor de Farmanguinhos, diretor da Anvisa e diretor do Lafepe, através da portaria no $1.415 / 07$ de 13/06/2007, com a finalidade de acompanhar o processo.

Em paralelo, na intenção de garantir o abastecimento do insumo farmacêutico, evitando a dependência de importação do princípio ativo, Farmanguinhos realizou esforços para a pré-qualificação de empresas farmoquímicas sediadas no território nacional. A escolha foi baseada em critérios técnicos e objetivos aferidos por uma banca examinadora composta por profissionais do quadro funcional de Farmanguinhos, Lafepe, DST/AIDS, Abifina, além de consultores técnicos e jurídicos. A ação, que veio ao encontro da política industrial ora estabelecida no Brasil através do PAC da Saúde, qualificou as empresas Globe Química Ltda, Cristalia Produtos Químicos Farmacêuticos Ltda e Nortec Química S.A. para o fornecimento de efavirenz (ifa) para que Farmanguinhos e LAFEPE pudessem ter garantias quanto à qualidade do princípio ativo para o desenvolvimento da formulação. 
As indústrias de farmoquímicos e de medicamentos constituem um setor industrial concebido de forma verticalmente integrada que requer um tratamento diferenciado dos demais setores industriais. No contexto econômico globalizado, o desenvolvimento de uma cadeia produtiva verticalizada, como a de fármacos e medicamentos, está diretamente relacionada tanto ao mercado, quanto à produção de intermediários de síntese, com evidente incentivo ao desenvolvimento e fabricação do princípio ativo utilizado como base para o medicamento.

Desta forma, a inovação trazida ao âmbito nacional a partir do Licenciamento Compulsório das patentes relacionadas à tecnologia de fabricação tanto do insumo farmacêutico Efavirenz, quanto do medicamento a que dá origem ao Sustiva $₫$, evidencia que a política adotada, em tempo, pelo governo federal, com a participação ativa de Farmanguinhos, permitiu a verticalização da produção nacional, agregando inovação tecnológica aos diversos segmentos da cadeia produtiva farmacêutica nacional, e vem ao encontro da necessidade iminente de viabilizar o fortalecimento da Indústria Farmoquímica Nacional com vistas a incrementar o já ativo Complexo Industrial da Saúde, além de inserir no contexto nacional uma indústria internacionalmente competitiva.

Os requisitos para o desenvolvimento de uma tecnologia com base no licenciamento compulsório trazem, em seu bojo, a obrigatoriedade do cumprimento de alguns prazos, com intuito de garantir que o país que licencia tenha o comprometimento de desenvolver, produzir e comercializar o produto e não se beneficie apenas da garantia de poder importar de outrem a tecnologia licenciada.

Assim, para garantir o cumprimento desses prazos, no Decreto 6108/ 07, fez-se necessário a constituição de um Comitê Técnico Regulatório, no âmbito da ANVISA, com a finalidade de acompanhar o desenvolvimento, a produção e o registro do medicamento, que garantisse o cumprimento, de forma igualitária, as exigências regulatórias aplicadas a todas as empresas privadas instaladas no território nacional.

É importante relembrar que, de acordo com a legislação vigente, Lei 9279/96, art. 24, O relatório deverá descrever, clara e suficientemente, o objeto, de modo a possibilitar sua realização por técnico no assunto e indicar, quando for o caso, a melhor forma de execução. Logo, a patente deve conter informações que possibilitem a um técnico versado na tecnologia a reprodução total do objeto por ela protegido. No entanto, é prática comum que o know how das tecnologias descritas e protegidas por patentes sejam claramente omitidas, sem nenhum ônus para o requerente.

De um processo completo iniciado com a negociação para um possível licenciamento voluntário, passando por um licenciamento compulsório e culminando em produção e abastecimento do PNDST/AIDS, com medicamento 
de qualidade e eficácia garantidas, cujo primeiro lote de foi entregue no dia 16 de fevereiro de 2009, ao Ministro da Saúde José Gomes Temporão, o Brasil fortalece sua imagem para o mundo e garante novos investimentos por demonstrar a que veio através da comprovada capacidade de uma equipe técnica ética, comprometida com a consolidação das políticas públicas de saúde do país.

Como resultado do processo, vê-se, explicitamente, uma política industrial fortalecida, ao passo que resulta deste ato uma parceria entre empresas de capital nacional e laboratórios oficiais, o que demonstra claramente que a possibilidade e a garantia de uma continuidade das ações de Parcerias para o Desenvolvimento Produtivo, e o fortalecimento contínuo da Indústria Farmoquímica Nacional, estão intimamente ligadas às Políticas Públicas de Saúde.

\subsection{Tenofovir}

Devido à precariedade do exame de pedidos de patente pelo INPI, algumas patentes referentes a produtos e processos farmacêuticos podem vir a ser concedidas de forma irregular e manter privilégio ilegal com prazo de validade maior que os 20 anos, como definidos pela LPI 9.279/96, em face do disposto no $\S$ único do art. 40.

Art. 40. A patente de invenção VIGORARÁ PELO PRAZO DE 20 (VINTE) ANOS e a de modelo de utilidade pelo prazo 15 (quinze) anos contados da data de depósito.

Parágrafo único. O prazo de vigência não será inferior a 10 (dez) anos para a patente de invenção e a 7 (sete) anos para a patente de modelo de utilidade, a contar da data de concessão, ressalvada a hipótese de o INPI estar impedido de proceder ao exame de mérito do pedido, por pendência judicial comprovada ou por motivo de força maior.

Dessa forma, o estudo propicia a identificação dessas irregularidades a fim de que se possa atuar oportunamente junto ao INPI, no curso do processo, para evitar tanto a concessão quanto extensão indevida do privilégio a produtos e processos farmacêuticos.

Logo, o estudo foi levado a cabo na intenção de se evidenciar a situação patentária da tecnologia de fabricação do insumo farmacêutico Tenofovir, bem como do medicamento que origina - Viread ${ }^{\circledR}$ - com a finalidade de identificar as estratégias possíveis para ação do Ministério da Saúde.

A busca de dados na base de dados do INPI elucidou a situação patentária do medicamento no país dando conta que ainda não há patente concedida no Brasil para o princípio ativo - Tenofovir - apontando apenas a existência de um pedido de patente PI 9811045-4 ainda em análise e, se concedido, vigoraria até 23/7/2018. 
Identificada a situação, passou-se a análise do dito pedido de patente. Nas buscas realizadas, foram encontradas evidências da ausência de novidade e de atividade inventiva, para objeto reivindicado, fato que direcionou a estratégia para a apresentação do subsídio ao exame.

Em dezembro de 2005 e maio de 2006, foram protocolados por FARMANGUINHOS, junto ao INPI, dois subsídios ao exame do pedido de patente. No entanto, os subsídios apresentados ao INPI não poderiam ser analisados enquanto não fosse declarado o interesse público do medicamento devido à uma ordem interna detalhada através da Resolução 126/06 que dita as novas regras para a realização do exame prioritário do pedido.

Inserido no programa DST/AIDS desde 2003, o medicamento é produzido e comercializado pelo laboratório Gilead em comprimidos de 300 mg e integra o grupo de 17 drogas essenciais que compõem o protocolo de tratamento do Ministério da Saúde para o Programa Nacional de DST/AIDS.

No exercício de 2006, e para a execução das aquisições de 2007, o Ministério da Saúde conseguiu uma redução significativa no preço praticado para o medicamento, cuja unidade farmacêutica vinha sendo vendida a US $\$ 7,28$, fechando o biênio $2007 / 2008$ a US\$3,80 a unidade, o que tem gerado um gasto em torno de $\mathrm{R} \$ 89$ bilhões/ano apenas com a aquisição deste medicamento, imprescindível para, pelo menos, 30 mil pacientes.

\section{2.a. Da atuação de Farmanguinhos no processo}

Em dezembro de 2005, a Farmanguinhos protocolou junto ao INPI um documento contendo argumentos que inviabilizariam a concessão da patente PI 9811045-4, de propriedade da Gilead, referente ao medicamento. Esta ação deflagrou sucessivas ações de organizações não governamentais resultando no questionamento das patentes já concedidas nos EUA para o tenofovir.

Segundo a nota divulgada pela Rede Brasileira pela Integração dos Povos - REBRIPii - desde 2006, diversas organizações que compõem o Grupo de Trabalho Sobre Propriedade Intelectual apresentaram subsídios técnicos ao INPI, corroborando com as colocações anteriormente apresentadas por Farmanguinhos. Através dos documentos apresentados demonstraram que o objeto do pedido de patente carecia de atividade inventiva (Art. $8^{\circ}$ e 13 da LPI) e davam conta que as formulações, ali reivindicadas, eram de domínio público desde a década de 80 , período em que o Brasil não privilegiava invenções referentes a produtos e processos farmacêuticos.

A dita patente vinha sendo questionada em diversos países, tais como Estados Unidos e, mais recentemente, a Índia, onde grupos de pessoas vivendo com HIV/AIDS apresentaram subsídios ao exame para a concessão da patente para o qual aguardam resposta. 
O termo «tenofovir» tem sido empregado quando se deseja fazer menção ao medicamento Viread®. Entretanto, para que se possa dar continuidade à discussão relacionada às substâncias que constituem os medicamentos, é necessário definir adequadamente as substâncias descritas em documentos (patentes, artigos e livros) publicados antes da data de prioridade unionista requerida por ocasião do depósito do PI9811045-4, ou seja, 25/07/1997.

Assim, através de busca realizada, foram encontradas as descrições das seguintes substâncias: Tenofovir — também conhecido como PMPA; bis(POC)tenofovir - também denominado bis(POC)PMPA, ou tenofovir disoproxil; fumarato de tenofovir disoproxil — também conhecido por bis(POC)PMPA fumarato, ou tenofovir DF, ou BPPF, ou, ainda, pelo nome comercial Viread®.

Através dos estudos realizados pela equipe de assessoria em propriedade industrial de Farmanguinhos, identificou-se que:

A substância de Fórmula I, tenofovir, não está protegido por patente no Brasil; entretanto, o medicamento contendo este composto só pode ser administrado por via injetável, caso contrário, seriam necessárias várias administrações orais para alcançar o mesmo efeito do injetável. Pode-se pensar em fazer injeção com este princípio ativo, mas este tipo de administração seria de difícil aderência pelos portadores de HIV/AIDS.

A substância de Fórmula II, tenofovir disoproxil ou Bis(POC)PMPA, não está protegido por patente no Brasil; trata-se de uma pró-droga do tenofovir e foi desenvolvido de modo a ser administrado de forma oral. Vários artigos foram publicados mostrando a superioridade de atuação do mesmo em relação ao tenofovir.

A substância, fumarato de tenofovir disoproxil, ou Viread $\circledast$, ou tenofovir DF, é um sal formado da síntese do Bis(POC)PMPA com o ácido fumárico. A substância e o respectivo medicamento encontram-se protegidos nos EUA pela patente US5.935.946, enquanto no Brasil foi encontrado pedido de patente BR9811045-4 depositado no INPI, em fase de exame.

Encontrou-se também, na busca, a patente US5.977.089, para qual não existe pedido de patente correspondente depositado no Brasil, que trata da substância (R)-bis(POC)PMPA, que é bem mais ativo que o seu correspondente $(\mathrm{S})$.

Observou-se ainda que, desde 1985, artigos científicos têm evidenciado a descrição da atividade antiviral do tenofovir e de substâncias análogas ao medicamento em diversos artigos e livros. O tenofovir, o bis (POC) tenofovir, e o fumarato de tenofovir disoproxil eram conhecidos antes de 1997, através de patentes depositadas em outros países.

Do exposto, evidencia-se que a análise das referências propiciou a confirmação da ausência de atividade inventiva do pedido de patente, pois a 
dita invenção trata, principalmente, da substância fumarato de bis(POC)PMPA. Obtê-lo através da reação de bis(POC)PMPA com ácido fumárico, cuja prática já está amplamente descrita nas referências citadas (GB942.152, DE2.111.071, US3.682.930, DE2.305.092, US3.994.974, BE859.425, US4.258.062, EP79.545, US4.430.343, EP240.228, US4.879.288, EP164.865 e US5.155.268), não apresenta efeito técnico inovador para um especialista no assunto, não merecendo proteção para a matéria requerida. Portanto, as reivindicações relacionadas a esta matéria também carecem de atividade inventiva.

Das referências analisadas durante o estudo, infere-se que a substância fumarato de tenofovir disoproxil refere-se ao sal da pró-droga tenofovir disoproxil, obtido por meio de sua reação com ácido fumárico.

Face ao exposto, foi elaborado o documento que, apresentado ao INPI como subsídio ao exame do analisado pedido, comprova a ausência de atividade inventiva, através do qual foi requerido o indeferimento do pedido, vez que a matéria reivindicada carece de atividade inventiva. A produção de fumarato de bis(POC)PMPA, sem diferenciação do que já há descrito na literatura técnica, não apresenta efeito técnico inventivo, para um técnico no assunto, face as referências citadas.

Em virtude desta ação, o técnico do INPI responsável pela análise do pedido exarou, em 08/04/2008, parecer de ciência ao depositante, dando conta da impossibilidade de concessão da patente requerida devido à constatação da ausência de atividade inventiva, requisito básico para a concessão de patentes, insculpido no art. $8^{\circ}$ da Lei 9279/96 - Lei de Propriedade Industrial - LPI.

A partir da data de publicação do indeferimento, pelos trâmites normais do processamento, contam-se 90 dias de prazo para a manifestação do requerente a respeito dos questionamentos ali referidos.

Neste ínterim, depois de constatada a imprescindibilidade do medicamento para o tratamento dos pacientes arrolados no PN DST/AIDS, e evidenciados os altos custos do programa relativos à sua aquisição, o Ministro da Saúde, José Gomes Temporão, declarou o interesse público do tenofovir através da Portaria n. 681. de 8 de abril de 2008, atendendo a um dos requisitos do Art. $3^{\circ}$ da Resolução 132/06 do INPI, a fim de deflagrar a condição de exame prioritário ao pedido PI 9811045-4. Em atendimento à condição, o INPI publicou o deferimento de prioridade então reivindicada pelo Ministério em 13/05/2008.

Enfim, após os trâmites legais, a dita patente teve seu privilégio negado em 26/08/2008 acatando a já alegada ausência de novidade com base nos arts. 8 e e 13 da LPI. No entanto, aguarda-se a análise do recurso ao indeferimento impetrado pelo requerente, em tempo hábil, junto ao INPI. 
Caso seja confirmada a condição, ou seja, mantido o indeferimento do pedido de patente pelo INPI, e se a empresa não recorrera ao judiciário com intuito de questionar o indeferimento da patente no país, sobrevirá a possibilidade de se produzir o medicamento livremente em território nacional; a isso, o Ministério da Saúde se antecedeu firmando a PDP - Parceria para o Desenvolvimento Produtivo do Laboratório LAFEPE com a busca por parceiros que possam, através de acordo firmado, transferir a tecnologia a fim de viabilizar o desenvolvimento e a produção nacional, de forma verticalizada, do comprimido de Tenofovir $300 \mathrm{mg}$.

\section{Da propriedade industrial como ferramenta para a judicialização da saúde}

Com a finalidade de fortalecer a ação já implantada desde 2005, em meados do ano de 2007, foi aprovado pelo CNPq um projeto que visa a identificação de alvos de judicialização que viabilize a produção dos medicamentos de interesse do Ministério da Saúde com o objetivo principal de identificar e monitorar os pedidos de patentes que descrevam a metodologia necessária para a produção de medicamentos de interesse da saúde pública e que apresentem problemas jurídicos e/ou técnicos que possam ser questionados judicialmente.

Com intuito de alcançar o objetivo, o projeto tem seguido, em princípio, 6 etapas básicas para a realização da prospecção e monitoramento conforme descrito abaixo:

a. Identificação:

Identificar os medicamentos de interesse do Ministério da Saúde para a dispensação no Sistema Único de Saúde (SUS).

b. Mapeamento:

Mapear a situação patentária do medicamento no mundo, em especial no Brasil, apontando os objetos protegidos no país que possam impedir a fabricação do Insumo Farmacêutico ou das diversas composições contendo o princípio ativo.

Buscar e identificar todos os artigos científicos, pedidos de patente, e patentes, que discorram sobre o Insumo Farmacêutico, o medicamento e as tecnologias envolvidas na produção destes, que possam basear uma argumentação sólida contra a concessão indevida de outras patentes.

c. Coleta:

Obter cópias dos autos dos processos dos pedidos de patentes ou patentes, depositadas junto ao INPI, que venham a ser objeto de análise.

Obter cópias dos artigos científicos identificados. 

patentes.

Pré-análise das informações extraídas das bases de dados e das

Identificar e analisar os documentos americanos, europeus e brasileiros de patente referentes aos medicamentos de interesse.

d. Tratamento da informação

Análise dos autos dos pedidos de patentes brasileiras a fim de:

Delimitar os objetos específicos de proteção de cada um deles;

Detectar as irregularidades técnicas e jurídicas que possam ser questionadas;

Identificar as irregularidades e indicar as estratégias a serem adotadas em cada caso informando as implicações técnicas e jurídicas envolvidas.

Leitura e elaboração de resumos dos Artigos científicos pertinentes à tecnologia em questão, a fim de delimitar o estado da técnica decorrente de pesquisas anteriormente realizadas.

e. Elaboração de pareceres técnico-jurídicos para cada medicamento

Elaborar parecer técnico-jurídico para cada medicamento apresentando as Estratégias e/ou Bases Jurídicas que permitam o Desenvolvimento Tecnológico: Subsídio ao exame técnico do INPI; Exceção Bolar; Licença Voluntária; Licença Compulsória; Nulidade da Patente (Administrativa ou Judicial).

Elaborar de parecer técnico-jurídico a ser protocolado no INPI para subsidiar o exame técnico do corpo de especialistas.

\subsection{Do Armazenamento e organização dos dados}

As informações geradas a partir da metodologia acima citada serão consolidadas em uma base de dados interativa que possibilitará o gerenciamento de todos os resultados obtidos a partir dos dados analisados e garantirá o acesso dos gestores. A base de dados terá a finalidade de organizar e relacionar as informações relevantes, relacionando os medicamentos às suas patentes de forma que dê ao usuário, administrador de conteúdo, liberdade, maleabilidade e acessibilidade para administrar estas informações de forma célere, segura e organizada.

A dita base será atualizada constantemente pelos especialistas responsáveis pelos estudos e estará disponível para subsidiar aos pesquisadores de Farmanguinhos, com informações pertinentes aos processos de obtenção dos insumos farmacêuticos ativos (ifas) e/ou formulações para medicamentos, entre outros, além de permitir aos gestores 
de Farmanguinhos e do Ministério da Saúde decidir, com base em informações confiáveis, sobre a situação patentária do medicamento, tanto no país, quanto em âmbito mundial.

Inicialmente, a base de dados foi desenvolvida em parceria com a Tecnologia da Informação ( $\mathrm{TI}$ ) dentro do formato padrão da intranet de Farmanguinhos. O sistema em questão é composto por controles semanticamente distintos e relacionados em prol da estrutura da informação planejada para o registro de medicamentos e respectivas patentes.

Foram considerados relevantes para cada registro as informações que caracterizam química e farmaceuticamente cada medicamento, vinculado aos dados referentes aos documentos de patentes americano, europeu e brasileiro de maior relevância. Até o momento a base de dados contempla informações e pareceres dos medicamentos antirretrovirais (ARVs).

\section{REFERÊNCIAS BIBLIOGRÁFICAS}

ASSOCIAÇÃO BRASILEIRA DE REDES DE FARMÁCIAS E DROGARIAS. ABRAFARMA em números. 2010. Disponível em: <http://www.abrafarma.com.br/ imprensa.htm>. Acessado em: 12 abr. 2010.

BERMUDEZ, J. A. Z. Indústria farmacêutica, Estado e sociedade: crítica da política de medicamentos no Brasil. São Paulo: Hucitec-Sociedade Brasileira de Vigilância em Medicamentos, 1995. 204 p.

BERMUDEZ, J. A. Z.; EPSZTEJN, R., Oliveira, M. A.; HASENCLEVER, L. O Acordo TRIPS da OMC e a proteção patentária no Brasil: mudanças recentes e implicações para a produção local e o acesso da população aos medicamentos. Rio de Janeiro: Escola Nacional de Saúde Pública; Fundação Oswaldo Cruz, 2000. 131 p.

BRASIL. Ministério da Saúde. Portaria n. 3.916, 1998.

Presidência da República. Lei n. 9.787, de 10 de fevereiro de 1999.

Presidência da República. Decreto 6108, de 04 de maio de 2007.

Presidência da República. Decreto n. 75.572, de 8 de abril de 1975.

Presidência da República. Lei n. 9.279, de 14 de maio de 1996.

CANCHUMANI, Roberto Mario Lovón. A produção de fármacos e medicamentos no Brasil e na Índia: uma análise comparativa (1995-2001). In: CONGRESSO INTERNACIONAL EM INOVAÇÃO E GERENCIAMENTO (ICIM 2009): GERENCIAMENTO DE INOVAÇÕES VOLTADO AO DESENVOLVIMENTO SUSTENTÁVEL, 6. 2009, São Paulo, 2009.

CENTRO BIOMEDICINA MOLECULAR E ESTRUTURAL. Disponível em: $<$ http://www.cbme.ualg.pt/>. 
CENTRO DE BIOTECNOLOGIA MOLECULAR E ESTRUTURAL. Disponível em: <http://cbme.if.sc.usp.br/>. Acesso em: 14 nov. 2007.

CHAUDHURI, S. The WTO and India's pharmaceuticals industry: patent protection, TRIPS and developing countries. Londres: Oxford University Press, 2005. p. 376.

CHAVES, Gabriela Costa; OLIVEIRA, Maria Auxiliadora; HASENCLEVER, Lia; MELO, Luíz Martins de. Evolução do sistema internacional de propriedade intelectual. Caderno de Saúde Pública, Rio de Janeiro, v. 23, n. 2, p. 257267, fev. 2007. Disponível em: <http://www.scielosp.org/scielo. php?script=sci_arttext\&pid=S0102-311X200700 0200002 \& Ing=en\&nrm= iso.> Acesso em: 28 jul. 2007.

CORREA, Carlos. M., MUSUNGU, Sisule. F. The WIPO patent agenda: the risks for developing countries. South Centre, Geneva, Nov. 2002. Disponível em: <http://www.southcentre.org/index.php?option=com_content\&task=view\& $\mathrm{id}=76 \&$ Itemid $=67>$.

A DECISÃO de Taiwan na Concessão de Licença Compulsória. Escritório de Propriedade Intelectual Taiwanês, Taiwan. Disponível em: <http://www.roctaiwan.org.br/event/ 20051223/ 2005122301.html>. Acesso em: 20 ago. 2007.

DI-BIASI, G.; GARCIA, M. S.; MENDES, P. P. M. A propriedade industrial: os sistemas de marcas, patentes e desenhos industriais analisados a partir da Lei número 9.279, de 14 de maio de 1996. Rio de Janeiro: Forense Universitária, 2002.

EFAVIRENZ: questões sobre o licenciamento compulsório. Ministério da Saúde. 2008. Disponível em: <http://www.deolhonaspatentes.org.br/media/ file/Casos/Brasil/release_ms_questoes.pdf>. Acesso em: 13 abr. 2010.

GADELHA, Carlos Augusto Grabois. O complexo industrial da saúde e a necessidade de um enfoque dinâmico na economia da saúde. Ciência \& Saúde Coletiva, Rio de Janeiro, v. 8, n. 2, p. 521-535, 2003.

GONTIJO, C. Propriedade Industrial no século XXI: direitos desiguais. Brasília: Instituto de Estudos Socioeconômicos/Rede Brasileira pela Integração dos Povos/Comércio com Justiça/Oxfam International, 2003.

HASENCLEVER, L.; CASSIOLATO, J.E. Capacitación tecnológica empresarial brasileña y transferencia de tecnología. Revista de Economía y Empresa, v. 34, p. 15-32, 1998.

IMS. Disponível em: <ttp://www.imshealth.com>.

A INDÚSTRIA Química e de Fármacos. Brasília: Ministério da Ciência e Tecnologia - MCT, 2001 (Livro Verde da Conferência Nacional de Ciência, Tecnologia e Inovação).

LUCCHESI, G. Dependência e autonomia no setor farmacêutico: um estudo da CEME. 1991. Dissertação (Mestrado), Escola Nacional de Saúde Pública/ Fiocruz, Rio de Janeiro, 1991. 330 p. 
NORWALK, CT. IMS Health forecasts global pharmaceutical market growth of $4-$ 6 Percent in 2010. IMS Health. Disponível em: <http://customerportal.imshealth.com/ portal/site/imsportal/menuitem.ed898ffec3ce21e8902eb452a418c22a/ ?vgnextoid=944216a3e5ac0210VgnVCM100000ed152ca2RCRD\&vgnextchannel $=$ cef40db9e2e97110VgnVCM10000071812ca2RCRD\&vgnextfmt=defaulten>. Acesso em: 31 mar. 2010.

O'DONNELL, G. Reflexões sobre os estados burocráticos autoritários. São Paulo: Vértices, 1987.

PALMEIRA FILHO, P. L.; PAN, S. S. K. Cadeia farmacêutica no Brasil: avaliação preliminar e perspectivas. Gerência de Químicos para a Saúde do BNDES. Rio de Janeiro, 2003. Disponível em: <http://www.bndes.gov.br/ conhecimento/bnset/set1801.pdf> Acessado em 27 jul. 2007.

PEDROSA, D. E.; GEREZ, J. C. Produção de Fármacos, questão de sobrevivência. Revista Brasileira de Tecnologia, v. 18, n. 3, p. 14-17, 1988.

REBRIP. Grupo de Trabalho sobre Propriedade Intelectual. Nota sobre a não concessão da patente do Tenofovir no Brasil. Disponível em: <http:// www.fenafar.org.br/pdf/carta-rebrip.pdf>. Acessado em: 02 fev. 2009.

SOARES, Anna Cristina Ribeiro Pereira. Mercado Farmacêutico. fev. 2010. Disponível em : <http://www.webartigos.com/articles/32333/1/MercadoFarmaceutico/pagina1.html>. Acessado em: 09 abr. 2010.

THE BEGINNING. Genebra: Organização Mundial de Propriedade Intelectual, 2003.

VELÁSQUEZ, G., BOULET, P. Globalization and access to drugs: perspectives on the WTO/TRIPS Agreement. Genebra: Organização Mundial de Saúde,1999.

WORLD TRADE ORGANIZATION: declaration on the TRIPS agreement and public health. Geneva: Organização Mundial de Saúde, 2001. 